\title{
Correction to "Pharmacology and Molecular Mechanisms of Clinically Relevant Estrogen Estetrol and Estrogen Mimic BMI-135 for the Treatment of Endocrine-Resistant Breast Cancer"
}

\begin{abstract}
The above article [Abderrahman B, Maximov PY, Curpan RF, Hanspal JS, Fan P, Xiong R, Tonetti DA, Thatcher GRJ, and Jordan VC (2020) Mol Pharmacol, 98: 364-381; DOI: https:// doi.org/10.1124/molpharm.120.000054] was incorrectly identified as an emerging concepts article when the copyedited and formatted version went online. It is a regular article. The HTML and PDF versions have been corrected.
\end{abstract}

The compositor apologizes for any inconvenience caused by this error. 